\title{
Lipid Peroxidation in Newborn Rabbits: Effects of Oxygen, Lipid Emulsion, and Vitamin $\mathbf{E}^{1}$
}

\author{
JON R. WISPE,${ }^{2}$ MATTHEW KNIGHT, ${ }^{3}$ AND ROBERT J. ROBERTS \\ Division of Neonatology, Department of Pediatrics, University of Iowa, College of Medicine, \\ Iowa City, lowa 52242
}

\begin{abstract}
The extent of in vivo lipid peroxidation and the in vivo antioxidant effects of $\alpha$-tocopherol and $\alpha$ tocopheryl acetate were studied in newborn rabbits exposed to one of two oxidant stresses: hyperoxia $\left(\mathrm{FIO}_{2}>0.9\right)$ or parenteral lipid emulsion infusion. Lipid peroxidation was monitored by measurement of expired ethane and pentane, tissue thiobarbituric acid (TBA) reactants, and tissue lipid peroxides. Seventy-two $h$ of hyperoxia did not increase any of the parameters of lipid peroxidation although mortality was higher in oxygen exposed animals. $\alpha$-Tocopherol (100 $\mathrm{mg} / \mathrm{kg}$, intravenous) lowered expired hydrocarbons and tissue TBA reactants, but raised liver lipid peroxides in both air and hyperoxia exposed pups. Infusion of soybean oil emulsion increased production of ethane and pentane, liver TBA reactants, and lung lipid peroxides. Both $\alpha$ tocopherol and $\alpha$-tocopheryl acetate prevented the soybean oil emulsion induced increase in volatile hydrocarbons. $\alpha$ Tocopherol (100 mg/kg, intravenous) administration also prevented the increase in liver TBA reactants and lung lipid peroxides. In identically treated animals, $\alpha$-tocopheryl acetate administration decreased liver TBA reactants but had no effect on lung lipid peroxides. We conclude that $\alpha$ tocopherol reduces lipid peroxidation in newborn rabbits including animals exposed to hyperoxia or infused with lipid emulsions. $\alpha$-Tocopheryl acetate results in lower tissue $\alpha$-tocopherol concentrations and is less effective as an antioxidant in lipid emulsion infused rabbits. (Pediatr Res 20: 505-510, 1986)
\end{abstract}

\section{Abbreviations}

TBA, thiobarbituric acid

LOOH, lipid hydroperoxides

LOO ., lipid peroxy radicals

Modern neonatal care has improved the survival of low birth weight infants. Paramount for the survival of the low birth weight infant is the use of increased oxygen concentrations to support an immature cardiorespiratory system. However, the reduction in mortality has been associated with an increase in chronic morbidities. Among these are several complications associated

Received September 30, 1985; accepted January 24, 1986.

Address for correspondence and reprint requests Dr. Robert J. Roberts, M.D. Ph.D., Department of Pediatrics, University of Iowa Hospitals and Clinics, W-220 GH, Iowa City, IA 52242.

J.R.W. was supported by a Fellowship Award in Clinical Pharmacology from the Pharmaceutical Manufacturers Association.

'Presented in part before the annual meeting of the Society for Pediatric Research, Washington, D.C., May 1985.

${ }^{2}$ Present address Division of Neonatology, Department of Pediatrics, University of Cincinnati Medical Center, 231 Bethesda Avenue, Cincinnati, $\mathrm{OH}$ 45267-0541.

${ }^{3}$ Present address Division of Clinical Pharmacology and Ambulatory Pediatrics; Department of Pediatrics, University of Florida, Gainesville, FL 32603. with hyperoxic exposure, including bronchopulmonary dysplasia and retrolental fibroplasia.

The exact mechanism by which oxidant tissue damage occurs is not clear. Several lines of evidence support the hypothesis that oxidant injury is mediated by the generation of partially reduced oxygen species (1-3). These reactive species may damage tissues by peroxidation of lipids, oxidation of proteins and nucleic acids, or through yet undefined mechanisms. It has long been presumed that polyunsaturated fatty acids in membranes are particularly susceptible to oxidative processes, and that "lipid peroxidation" is a central feature of oxygen-associated tissue damage. Lipid peroxidation is associated with the generation of lipid-derived intermediate products including lipid hydroperoxides, hydroxyaldehydes, and malonaldehyde. These intermediates may be important in the damage process, because they also are very reactive and can propagate further oxidizing reactions (4).

The mature human organism possesses protective mechanisms to detoxify both reactive oxygen metabolites and the lipid-derived intermediates. These include enzymatic (superoxide dismutase, catalase, and the glutathione system) and nonenzymatic factors (sulfhydryl containing amino acids and vitamins $\mathrm{E}$ and C) (3). In the newborn, particularly the preterm newborn, protective systems may not be fully active, in part because the nutritional sources of antioxidant vitamins and necessary cofactors for the protective enzymes are insufficient $(5,6)$. Despite these "deficiencies," most newborn animal species appear to be resistent to oxygen-induced toxicities (7). However, the conclusion that newborns are resistant to oxidative injury is based on mortality data which may not reflect the importance of vitamin $E$ and the antioxidant enzyme systems to individual tissues or organs. For example, newborn animals suffer severe lung damage after exposure to hyperoxia (5), and their resistence to oxygen-related mortality may reflect the ability of metabolically active tissues to repair themselves. Despite the unresolved questions regarding the biochemical origin of oxygen-induced injury, vitamin $E$ has been administered to neonates in an attempt to protect against oxygen-induced tissue damage. Although the therapeutic experience with vitamin $\mathrm{E}$ is now extensive, controversy continues regarding the appropriate indications and dosage for vitamin $\mathrm{E}$ therapy $(8,9)$.

This report presents the results of experiments designed to test the hypothesis that lipid peroxidation is increased by oxidative challenges in the newborn. Three experimental conditions were utilized to explore the extent of lipid peroxidation in newborns. The first experiments examined the effect of oxygen on biochemical parameters of in vivo lipid peroxidation in newborn rabbits. To further test the hypothesis that hyperoxic exposure increases in vivo lipid peroxidation, the antioxidant effectiveness of $\alpha$ tocopherol was examined in newborn rabbits exposed to room air or hyperoxia. The final series of experiments examined the parameters of lipid peroxidation after infusion of lipid emulsions while comparing the relative antioxidant effectiveness of $\alpha$-tocopherol and $\alpha$-tocopheryl acetate. The acetate ester of the 
naturally occurring isomer is the commercial form of vitamin $\mathrm{E}$ most commonly available. However, the esterified form is probably not active as an antioxidant until the acetate group is removed (10). In addition, the tissue disposition of intravenous $\alpha$-tocopheryl acetate is very different from that of $\alpha$-tocopherol (8). We compared these two forms of vitamin $E$ in newborn rabbits receiving lipid emulsion infusion, a clinically relevant situation in which lipid peroxidation is increased.

\section{MATERIALS AND METHODS}

The studies to investigate our objectives were conducted in three separate protocols. White New Zealand pregnant rabbits of known gestation, purchased from Morrison Rabbitry (West Branch, IA), were delivered by cesearian section on day 31 of gestation using $2.5 \%$ halothane in oxygen and local anesthesia with $1 \%$ lidocaine. After delivery, the pups were placed in an infant isolette (Air Shields, Inc., Hatboro, PA) with an air temperature of $34^{\circ} \mathrm{C}$. After a 1 -h recovery period, the pups were weighed, marked, and one of three protocols instituted. None of the pups in these studies received any enteral feedings, but all received twice daily parenteral fluids consisting of glucose and electrolytes ( $1 \mathrm{ml} / 10 \mathrm{~g}$ body weight) by subcutaneous clysis.

Room air versus hyperoxia. The first set of experiments was designed to study the effects of hyperoxia $\left(\mathrm{FIO}_{2}>0.9\right)$ on lipid peroxidation in the presence or absence of $\alpha$-tocopherol. Immediately after delivery, pups in each litter were randomized into two groups, one-half of the pups were placed in room air and the other half in hyperoxia. The duration of exposure was 3 days. One half of the animals in both the room air and the hyperoxia groups received $100 \mathrm{mg} / \mathrm{kg}$ of $\alpha$-tocopherol (provided by Hoffmann-LaRoche, Nutley, NJ) intravenously at $4 \mathrm{~h}$ of age. The Hoffman-LaRoche product is compounded in $10 \%$ Emulphor 620 (a polyoxyethylated vegetable oil), 10\% ethyl alcohol, $10 \%$ propylene glycol, $0.03 \%$ sodium acetate, $0.25 \%$ acetic acid, $0.01 \%$ EDTA, and $0.9 \%$ saline. The $\mathrm{pH}$ is adjusted to 4 with sodium hydroxide (11). Vehicle-treated controls received this same preparation without vitamin E. Expired ethane and pentane were quantitated in each rabbit at the end of the 3-day exposure period. After analysis of expired hydrocarbons, the animals were killed with sodium pentobarbital (intraperitoneal), and blood, liver, and lungs removed for analysis of $\alpha$-tocopherol concentration, TBA reactants, and lipid peroxides.

Safflower oil emulsion infusion. Previously we have shown that infusion of safflower oil emulsion (Liposyn 10\%, Abbott Laboratories, Chicago, IL) increases expired pentane in newborn humans and rabbits (11). The second series of experiments was designed to evaluate the antioxidant effects of $\alpha$-tocopherol on lipid emulsion-enhanced lipid peroxidation in the newborn rabbit. The pups that received safflower oil emulsion without vitamin E have been reported previously (12), and are included in this report to facilitate comparison with littermates that received safflower oil emulsion and vitamin $\mathrm{E}$. Within $8 \mathrm{~h}$ of delivery, the pups were anesthetized with $15 \mathrm{mg} / \mathrm{kg}$ of sodium pentobarbital intraperitoneally and indwelling intravenous catheters (24 gauge, Critikon, Inc., Tampa, FL) inserted into the right external jugular vein. One-half of the pups received a single, intravenous dose of $100 \mathrm{mg} / \mathrm{kg}$ of $\alpha$-tocopherol immediately prior to beginning the lipid emulsion infusion. The other half of the pups did not receive $\alpha$-tocopherol. The average dose of lipid was $4 \mathrm{~g} / \mathrm{kg}$ for both groups and was administered by continuous infusion over $20 \mathrm{~h}$. Littermate, control animals, received parenteral glucose and electrolytes but no lipid emulsion, $\alpha$-tocopherol, or vehicle. All pups were studied for production of volatile hydrocarbons at the conclusion of the $20 \mathrm{~h}$ lipid infusion and then killed and blood, liver, and lungs removed for determination of $\alpha$-tocopherol concentration and TBA reactants.

Soybean oil emulsion infusion. The relative antioxidant effectiveness of $\alpha$-tocopherol and $\alpha$-tocopheryl acetate was compared in newborn rabbits receiving a continuous infusion of soybean oil emulsion (Intralipid, 10\%, Cutter Biological, Emeryville, CA). Soybean oil emulsion was used because it contains approximately $5-10 \mathrm{mg} / \mathrm{liter}$ of $\alpha$-tocopherol, compared to safflower oil emulsion which contains $25-30 \mathrm{mg} /$ liter (13). Indwelling intravenous lines were placed, and $\alpha$-tocopherol or $\alpha$-tocopheryl acetate $(100$ $\mathrm{mg} / \mathrm{kg})$, or vehicle placebo $(2 \mathrm{ml} / \mathrm{kg})$ was given intravenously immediately prior to lipid emulsion infusion. $\alpha$-Tocopherol was administered as obtained from Hoffmann-LaRoche. As outlined above, the vehicle for the Hoffmann-LaRoche preparation differs from other available parenteral preparations. Pure $\alpha$-tocopheryl acetate (Sigma Chemical, St. Louis, MO) was formulated in the same Emulphor 620 containing vehicle as the HoffmannLaRoche $\alpha$-tocopherol. All lipid infused animals received an average dose of $3.7 \mathrm{~g}$ of lipid $/ \mathrm{kg}$, infused over $20 \mathrm{~h}$. The pups were studied for production of volatile hydrocarbons following completion of the lipid infusion. The animals were then killed, and liver and lungs removed for determination of tissue TBA reactants, tissue $\alpha$-tocopherol and $\alpha$-tocopheryl acetate concentrations, and tissue lipid peroxide content.

Analysis of hydrocarbons. Hydrocarbons were analyzed using gas-liquid chromatography as previously described $(14,15)$. Animals were placed in a 1.4-liter glass-topped, stainless steel chamber which was part of a closed, recirculating system. The atmosphere in the closed system was circulated continuously through soda lime. Oxygen consumption was monitored by means of a water manometer, and the oxygen consumed replaced with hydrocarbon-free oxygen. For analysis of hydrocarbons in the expired air of the rabbit, a 6-ml aliquot of gas from the closed system was injected into the gas chromatograph via a six-way valve connected to the recirculating system. Hydrocarbon content of the system was measured at the beginning and the end of a 60 -min period. The difference in ethane and pentane between the two samples represented hydrocarbons excreted by the rabbit pup. The rate of hydrocarbon production is expressed as pmol/ $100 \mathrm{~g}$ body weight per min.

Analysis of thiobarbituric acid reactants. Lung and liver TBA reactants were quantitated on fresh tissue. The organs were removed, washed in cold isotonic phosphate buffer, and carefully blotted dry. One hundred $\mathrm{mg}$ of tissue were homogenized in ice cold aqueous $1.15 \% \mathrm{KCl}$. For the first two protocols, liver and lung TBA reactants were quantitated spectrophotometrically (16), and the results reported as the difference between absorption of 532 and $520 \mathrm{~nm}$. For the soybean oil emulsion studies, tissue TBA reactants (Table 7) were quantitated using a modification of the fluorometric method (17). To prevent the production of TBA reactants during the assay procedure (18), $1 \mathrm{mM}$ deferoxamine was added to each homogenate. Blood TBA reactants were determined by the fluorometric micromethod of Yagi (19).

Other analyses. Tissue vitamin E concentrations were quantitated using high-pressure liquid chromatography (20) which measures both $\alpha$-tocopherol and $\alpha$-tocopheryl acetate.

Lipid peroxides present in the lungs and liver were measured as described by Hicks and Gebicki (21). This assay measures the release of triiodide ions when peroxides present in tissue extracts react anaerobically with excess potassium iodide.

Statistical analysis. Parametric tests for significance at the $p<$ 0.05 level were used. For the air versus hyperoxia protocol, data were analyzed with a two-way ANOVA. Data from both lipid emulsion infusion protocols were analyzed with a one-way ANOVA. Newman-Keuls post hoc analyses were performed on those ANOVAs which were significant (22).

\section{RESULTS}

The effect of oxygen on lipid peroxidation in newborn rabbits that did not receive $\alpha$-tocopherol is shown in Table 1 . Animals not given $\alpha$-tocopherol had a 3-day mortality of $40 \%$ in hyperoxia and $0 \%$ in room air. However the 72-h exposure to hyperoxia did not significantly increase pentane production, TBA 
Table 1. Effect of oxygen on lipid peroxidation in newborn rabbits*

\begin{tabular}{|c|c|c|c|c|c|c|}
\hline \multirow[b]{2}{*}{ Groups } & \multirow{2}{*}{$\begin{array}{c}\text { Expired pentane } \\
(\mathrm{pmol} / 100 \mathrm{~g} / \\
\mathrm{min})\end{array}$} & \multicolumn{3}{|c|}{ TBA reactants $\dagger$} & \multicolumn{2}{|c|}{ Lipid peroxides $\ddagger$} \\
\hline & & Lung & Liver & Blood & Lung & Liver \\
\hline Room air $(n=6)$ & $3.3 \pm 1.7$ & $0.07 \pm 0.02$ & $0.34 \pm 0.2$ & $4.3 \pm 3$ & $245 \pm 31$ & $222 \pm 32$ \\
\hline Hyperoxia $\left(\mathrm{FIO}_{2}>0.9\right)(n=6) \S$ & $8.3 \pm 7$ & $0.05 \pm 0.03$ & $0.38 \pm 0.1$ & $5.4 \pm 3.5$ & $208 \pm 19$ & $280 \pm 34$ \\
\hline
\end{tabular}

$*$ Values represent mean $\pm \mathrm{SD}$. There were no significant differences in lipid peroxidation parameters between room air- and hyperoxia-exposed rabbit pups.

$\dagger$ Lung and liver values expressed as OD 532-OD 520; blood values expressed as $\mathrm{nmol} / \mathrm{ml}$.

$\$$ Expressed as nmol lipid peroxide/g tissue.

$\S 72 \mathrm{~h}$ mortality: $40 \%$ in pups in hyperoxia versus $0 \%$ in room air $(p<0.05)$.

Table 2. Effect of $\alpha$-tocopherol on lipid peroxidation in newborn rabbits*

\begin{tabular}{|c|c|c|c|c|c|c|}
\hline \multirow[b]{3}{*}{ Groups } & \multicolumn{6}{|c|}{ Lipid peroxidation parameters } \\
\hline & \multirow{2}{*}{$\begin{array}{c}\text { Expired pentane } \\
\text { (pmol/100 g/ } \\
\text { min) }\end{array}$} & \multicolumn{3}{|c|}{ TBA reactants $\dagger$} & \multicolumn{2}{|c|}{ Lipid peroxides $\$$} \\
\hline & & Lung & Liver & Blood & Lung & Liver \\
\hline$\alpha$-Tocopherol $(n=11)$ & $1.3 \pm 1.9 \S$ & $0.03 \pm 0.01 \|$ & $0.11 \pm 0.05$ & $0.4 \pm 0.1 \|$ & $251 \pm 62$ & $574 \pm 189 \|$ \\
\hline \multirow[t]{3}{*}{ Controls $(n=11)$} & $6.6 \pm 5.0$ & $0.07 \pm 0.02$ & $0.35 \pm 0.16$ & $4.9 \pm 3.0$ & $226 \pm 31$ & $248 \pm 43$ \\
\hline & \multicolumn{6}{|c|}{$\alpha$-Tocopherol tissue concentrations after $\alpha$-tocopehrol§ } \\
\hline & \multicolumn{3}{|c|}{ Lung } & \multicolumn{3}{|c|}{ Liver } \\
\hline $\begin{array}{l}\alpha \text {-Tocopherol }(n=11) \\
\text { Controls }(n=11)\end{array}$ & \multicolumn{3}{|c|}{$\begin{array}{c}162 \pm 42 \| \\
4 \pm 2\end{array}$} & \multicolumn{3}{|c|}{$\begin{array}{c}1722 \pm 280 \| \\
8 \pm 4\end{array}$} \\
\hline
\end{tabular}

* Newborn rabbits were given $\alpha$-tocopherol ( $100 \mathrm{mg} / \mathrm{kg}$ intravenous) or vehicle within $4 \mathrm{~h}$ of birth. Lipid peroxidation parameters were examined 3 days after $\alpha$-tocopherol administration. Values represent mean \pm SD.

$\dagger$ Lung and liver values expressed as OD 532-OD 520; blood values expressed as $\mathrm{nmol} / \mathrm{ml}$.

$\$$ Values expressed as nmol lipid peroxide/g tissue.

II Values represent tissue $\alpha$-tocopherol content in $\mu \mathrm{g} / \mathrm{g}$ tissue.

$\S p<0.05 ; \alpha$-tocopherol treated versus controls.

reactants in lung, liver or blood, or lipid peroxides in lung or liver.

The effect of $\alpha$-tocopherol on lipid peroxidation in newborn rabbits is shown in Table 2. Because there were no statistical differences between the room air- and hyperoxia-treated animals, the data in Table 2 are separated by $\alpha$-tocopherol or vehicle treatment, and not by air or hyperoxia exposure. Both air and oxygen exposed animals are included in the $\alpha$-tocopherol and vehicle groups. Expired pentane was lower in animals that received a single, intravenous dose of $100 \mathrm{mg} / \mathrm{kg}$ of $\alpha$-tocopherol. $\alpha$-Tocopherol also lowered TBA reactants in lung, liver, and blood. Lung and liver lipid peroxides with and without $\alpha$-tocopherol also are shown in Table 2. Three days after administration of $\alpha$-tocopherol, lipid peroxides in liver were significantly higher in the pups treated with $\alpha$-tocopherol than in the vehicletreated pups. All the differences between $\alpha$-tocopherol treated pups and controls are consistent, even when the data are separately analyzed within air or hyperoxia groups. The tissue $\alpha$ tocopherol concentrations of these animals 3 days after vitamin $\mathrm{E}$ administration are shown in the lower portion of Table $2 . \alpha$ Tocopherol, $100 \mathrm{mg} / \mathrm{kg}$, significantly raised $\alpha$-tocopherol concentrations in lung and liver.

In the second series of studies, the effect of intravenous $\alpha$ tocopherol on lipid emulsion-enhanced lipid peroxidation was studied. These data are shown in Table 3. All pups, except control, received approximately $4 \mathrm{~g}$ of lipid $/ \mathrm{kg}$ during a 20 -h infusion. Control pups received only parenteral fluids and no lipid emulsion or $\alpha$-tocopherol. Safflower oil emulsion infusion increased expired pentane, but not ethane. Administration of a single, intravenous, $100 \mathrm{mg} / \mathrm{kg}$ dose of $\alpha$-tocopherol significantly lowered expired pentane to levels that were not different from nonlipid infused controls. The TBA reactant data from these pups are shown in Table 4. Lung, liver, and blood TBA reactants were increased by safflower oil emulsion infusion when com-
Table 3. Pentane excretion during safflower oil emulsion infusion in newborn rabbits

\begin{tabular}{lcc}
\hline \multicolumn{1}{c}{ Groups* } & $\begin{array}{c}24-\mathrm{H} \text { lipid } \\
\text { dose } \\
(\mathrm{g} / \mathrm{kg} / \text { day })\end{array}$ & $\begin{array}{c}\text { Pentane } \dagger \\
(\mathrm{pmol} / 100 \mathrm{~g} / \\
\mathrm{min})\end{array}$ \\
\hline Controls $(n=5)$ & & $4 \pm 2 \ddagger$ \\
Lipid $(n=6)$ & $3.6 \pm 1.2$ & $100 \pm 70 \S$ \\
Lipid $+\alpha$-Tocopherol $(n=5)$ & $4.2 \pm 0.6$ & $11 \pm 8$ \\
\hline
\end{tabular}

* Control rabbits received no treatments. Lipid treated rabbits were infused with lipid emulsion over $20 \mathrm{~h}$; lipid-and $\alpha$-tocopherol-treated rabbits were given $\alpha$-tocopherol (100 $\mathrm{mg} / \mathrm{kg}$ intravenous) prior to lipid infusion. Values represent mean $\pm \mathrm{SD}$.

$\dagger$ Production of ethane was not different among any of the treatment groups.

$\ddagger p<0.05$; control versus lipid.

$\S p<0.05 ;$ lipid versus lipid $+\alpha$-tocopherol.

pared to nonlipid infusion controls that did not receive $\alpha$ tocopherol. Administration of $100 \mathrm{mg} / \mathrm{kg}$ of $\alpha$-tocopherol prevented the rise in liver and blood TBA reactants. Lung TBA reactants in animals given lipid emulsion and $\alpha$-tocopherol were intermediate between the other two treatment groups and not statistically different from either.

In the third and final series of experiments, the relative antioxidant effectiveness of $\alpha$-tocopherol and $\alpha$-tocopheryl acetate was compared in soybean oil emulsion-infused pups. $\alpha$-Tocopherol tissue concentrations in these animals are shown in Table 5. Administration of $\alpha$-tocopheryl acetate resulted in lower $\alpha$-tocopherol concentrations compared to pups given the same dose of $\alpha$-tocopherol. Lung $\alpha$-tocopherol concentrations after $\alpha$-tocopheryl acetate were not different from vehicle-treated pups. Animals given $\alpha$-tocopheryl acetate also had 250 and $35 \mu \mathrm{g} / \mathrm{g}$ tissue of $\alpha$-tocopheryl acetate in lung and liver, respectively. 
Table 4. TBA reactants in newborn rabbits after safflower oil emulsion infusion

\begin{tabular}{lllc}
\hline & \multicolumn{3}{c}{ Tissue TBA reactants $\dagger$} \\
\cline { 2 - 4 } \multicolumn{1}{c}{ Groups* } & \multicolumn{1}{c}{ Lung } & \multicolumn{1}{c}{ Liver } & Blood \\
\hline Controls $(n=5)$ & $0.07 \pm 0.02$ & $0.34 \pm 0.2$ & $4 \pm 3$ \\
Lipid $(n=6)$ & $0.15 \pm 0.06 \ddagger$ & $0.54 \pm 0.1 \ddagger$ & $77 \pm 15 \ddagger$ \\
Lipid $+\alpha$-tocopherol & $0.11 \pm 0.06$ & $0.38 \pm 0.2 \S$ & $21 \pm 19 \S$ \\
$\quad(n=5)$ & & & \\
\hline
\end{tabular}

* Values represent mean $\pm \mathrm{SD}$; data from same animals shown in Table 3 .

$\dagger$ Lung and liver values expressed as OD 532-OD 520; blood values expressed as $\mathrm{nmol} / \mathrm{ml}$.

$\ddagger p<0.05$; lipid versus control.

$\S p<0.05 ;$ lipid $+\alpha$-tocopherol versus lipid.

Table 5. Tissue vitamin $E$ concentrations after intravenous $\alpha$ tocopherol or $\alpha$-tocopheryl acetate administration

\begin{tabular}{lcc}
\hline \multicolumn{1}{c}{ Groups* } & \multicolumn{2}{c}{$\begin{array}{c}\text { Tissue } \alpha \text {-tocopherol } \\
\text { concentrations }(\mu \mathrm{g} / \mathrm{g} \\
\text { tissue) }\end{array}$} \\
\cline { 2 - 3 } & Lung & Liver \\
\hline$\alpha$-Tocopherol & $86 \pm 50 \dagger$ & $440 \pm 260 \top$ \\
$\alpha$-Tocopheryl acetate $(n=6) \ddagger$ & $17 \pm 8$ & $50 \pm 28 \S$ \\
Vehicle placebo $(n=5)$ & $6 \pm 4$ & $2 \pm 3$ \\
\hline
\end{tabular}

* All animals received $4 \mathrm{~g}$ lipid/ $\mathrm{kg}$ body weight over $20 \mathrm{~h}$ prior to analysis, and $100 \mathrm{mg} / \mathrm{kg}$ of $\alpha$-tocopherol equivalents as $\alpha$-tocopherol or $\alpha$-tocopheryl acetate intravenously immediatley prior to initiation of lipid emulsion infusion. Vehicle placebo-treated animals received lipid emulsion and an equivalent volume of Emulphor 620 vehicle. Data from these experimental protocol are also presented in Tables 6 and 7.

$\dagger p<0.05$; different from the other two treatment groups.

$\ddagger \alpha$-Tocopheryl acetate-treated animals also had $250 \pm 350$ and $35 \pm$ $25 \mu \mathrm{g} / \mathrm{g}$ of $\alpha$-tocopheryl acetate in lung and liver, respectively.

$\S p<0.05$; different from the other two treatment groups.

Table 6 presents the ethane and pentane data from the pups that received $10 \%$ soybean oil emulsion. Lipid-infused pups that received vehicle placebo produced more ethane and pentane than either $\alpha$-tocopherol or $\alpha$-tocopheryl acetate-treated pups. There were no differences in expired hydrocarbons between $\alpha$ tocopherol and $\alpha$-tocopheryl acetate treated pups. The tissue TBA reactant data and lipid peroxide data from these animals are shown in Table 7. TBA reactants were quantitated fluorometrically (17) using $1 \mathrm{mM}$ deferoxamine to prevent in vitro formation of reactant material (18). Because different TBA assay methods were used, the data in Table 7 are not comparable to TBA data in Tables 1, 2, and 4. Compared to nontreated controls, soybean oil emulsion infusion in the vehicle-treated pups increased liver TBA reactants and lung lipid peroxides. Both $\alpha$ tocopherol and $\alpha$-tocopheryl acetate prevented the rise in liver TBA reactants after soybean oil emulsion infusion. However, only $\alpha$-tocopherol prevented the increase in lung lipid peroxides after soybean oil emulsion infusion. $\alpha$-Tocopherol also reduced lung TBA reactants below control levels.

\section{DISCUSSION}

Recently there have been considerable, and often divergent, discussions about the value of increasing antioxidant capabilities in newborn human infants by pharmacologically supplementing with vitamin $E(8,23,24)$. However, until recently it has not been possible to assess rigorously the contributions of lipid peroxidation to tissue injury or the antioxidant effectiveness of vitamin $E$, in part because of difficulty in quantitating oxidizing
Table 6. Effect of $\alpha$-tocopherol and $\alpha$-tocopheryl acetate on expired hydrocarbons in soybean oil emusion infused newborn rabbits

\begin{tabular}{|c|c|c|}
\hline \multirow[b]{2}{*}{ Groups* } & \multicolumn{2}{|c|}{$\begin{array}{c}\text { Expired volatile } \\
\text { hydrocarbons }(\mathrm{pmol} / 100 \mathrm{~g} \\
\text { body } \mathrm{wt} / \mathrm{min})\end{array}$} \\
\hline & Ethane & Pentane \\
\hline$\alpha$-Tocopherol $(n=6)$ & $17 \pm 33$ & $26 \pm 33$ \\
\hline$\alpha$-Tocopheryl acetate $(n=5)$ & $16 \pm 10$ & $41 \pm 21$ \\
\hline Vehicle placebo $(n=5)$ & $148 \pm 68 \dagger$ & $268 \pm 126 \dagger$ \\
\hline
\end{tabular}

* See Table 5 for details of experimental treatments. Values represent mean \pm SD. Data from this experimental protocol are also represented in Tables 5 and 7.

$\dagger p<0.05$; vehicle placebo versus either $\alpha$-tocopherol or $\alpha$-tocopheryl acetate.

reactions in vivo (25). Various products of lipid peroxidation have been measured in attempts to define the extent of in vivo lipid peroxidation and the antioxidant activity of vitamin $E(10$, 26). Lipid hydroperoxides ( $\mathrm{LOOH})$ are intermediate products of polyunsaturated fatty acid peroxidation that can be measured directly in tissues. These peroxides can decompose to several products including malonaldehyde and volatile hydrocarbons. Malonaldehyde can be quantitated by reacting it with TBA, forming a chromophore with characteristic absorption and fluorescence spectra (27). Volatile hydrocarbons are produced by degradation of lipid hydroperoxides and are a sensitive index of lipid peroxidation which correlates well with other biochemical and morphologic parameters of lipid peroxidation $(26,28)$. In order to assess in vivo lipid peroxidation and antioxidant capabilities of vitamin $\mathrm{E}$, we measured $\mathrm{LOOH}$, TBA reactants, and volatile hydrocarbons in newborn rabbits treated with two clinically relevant oxidant stresses (oxygen, unsaturated lipids).

Our first objective was to investigate the effect of hyperoxia on lipid peroxidation. In rabbit pups, given no nutritional sources of vitamin $\mathrm{E}$ or other antioxidants, a 3-day exposure to oxygen $\left(\mathrm{FIO}_{2}>0.9\right)$ did not significantly increase any of the measured biochemical parameters of lipid peroxidation. These findings are in contrast to the increased mortality in the oxygen-treated pups (Table 1), and to the subjective impression that the oxygen survivors were in worse condition than the room air controls. Caution is urged in applying these data to overall conclusions about the contribution of lipid peroxidation in oxygen-associated damage. The biochemical processes of oxidative damage are the result of complex interactions between damaging and protective reactions, therefore focusing on a single component of the system can be misleading. Lipid peroxidation cannot be excluded as a mechanism for oxygen-associated tissue damage, because our results may reflect technical difficulties in assessing lipid peroxidation in vivo. However, these results do suggest that other oxidative reactions are likely to be important.

Our second objective was to examine the effects of $\alpha$-tocopherol on lipid peroxidation in newborn rabbits. A single injection of $\alpha$-tocopherol decreased lung, liver, and blood TBA reactants, and expired pentane in newborn rabbits exposed to either room air or hyperoxia. However, in these animals, $\alpha$-tocopherol administration increased liver, but not lung, lipid peroxides. These seemingly divergent effects are consistent with the antioxidant actions of $\alpha$-tocopherol. One accepted mechanism of action for $\alpha$-tocopherol is proton donation to reactive lipid species, particularly (LOO -) (10). The increased tissue $\alpha$-tocopherol concentrations that result from a single, large dose of $\alpha$-tocopherol could convert LOO to the more stable lipid peroxides ( $\mathrm{LOOH}$ ) thus decreasing peroxy radical decomposition to TBA reactants and volatile hydrocarbons. After a intravenous dose of $\alpha$-tocopherol, $\alpha$-tocopherol levels are much higher in the liver than the lung (8). If the effect of $\alpha$-tocopherol on lipid peroxide formation is concentration dependent, then this difference in $\alpha$-tocopherol 
Table 7. Effect of $\alpha$-tocopherol and $\alpha$-tocopheryl acetate on tissue TBA reactants and tissue lipid peroxides in soybean oil emulsioninfused newborn rabbits

\begin{tabular}{|c|c|c|c|c|}
\hline \multirow[b]{2}{*}{ Groups* } & \multicolumn{2}{|c|}{$\begin{array}{c}\text { TBA levels } \dagger \\
\text { (nmol/mg tissue) }\end{array}$} & \multicolumn{2}{|c|}{$\begin{array}{l}\text { Tissue lipid peroxides } \\
\text { (nmol/g tissue) }\end{array}$} \\
\hline & Lung & Liver & Lung & Liver \\
\hline$\alpha$-Tocopherol $(n=5)$ & $0.13 \pm 0.07 \ddagger$ & $0.29 \pm 0.20 \ddagger$ & $105 \pm 47 \S$ & $394 \pm 264$ \\
\hline$\alpha$-Tocopheryl acetate $(n=6)$ & $0.23 \pm 0.14$ & $0.78 \pm 0.5$ & $360 \pm 87$ & $389 \pm 115$ \\
\hline Vehicle placebo $(n=5)$ & $0.22 \pm 0.16$ & $1.20 \pm 0.4 \|$ & $459 \pm 341$ & $481 \pm 84$ \\
\hline Control $(n=7)$ & $0.21 \pm 0.06$ & $0.57 \pm 0.1$ & $177 \pm 599$ & $316 \pm 124$ \\
\hline
\end{tabular}

* See Table 5 for details of experimental treatments. All groups received lipid emulsion except controls. Control animals received no lipid emulsion and no $\alpha$-tocopherol or vehicle. Values represent mean \pm SD. Data from this experimental protocol are also presented in Tables 5 and 6.

$\dagger 1 \mathrm{mM}$ deferoxamine added to each homogenate prior to heating.

$\ddagger p<0.05$; different from the other three treatment groups.

$\S p<0.05 ; \alpha$-tocopherol versus $\alpha$-tocopheryl acetate or vehicle placebo.

$\| p<0.05$; different from the other three treatment groups.

I $p<0.05$; control versus $\alpha$-tocopheryl acetate or vehicle placebo.

tissue concentrations may explain why liver, but not lung, lipid peroxides were increased after $\alpha$-tocopherol. Knight et al. (29) observed a $50 \%$ reduction in in vitro lipid peroxidation in lung with $\alpha$-tocopherol concentrations of $30-100 \mu \mathrm{g} / \mathrm{g}$. These values are close to the $\alpha$-tocopherol concentrations which appeared to be necessary in our in vivo studies (Tables 5 to 7). Activity of other enzymes, particularly glutathione peroxidase, also are important in determining tissue TBA reactants and lipid peroxides (30). Activity of glutathione system enzymes is greater in liver than lung and may also explain the differences between liver and lung lipid peroxide levels after $\alpha$-tocopherol.

In vivo lipid peroxidation is increased by infusion of lipid emulsions in newborn humans and rabbits (12), and provides another model in which to study antioxidant effects of vitamin E. Human infants have decreased clearance of infused lipids (31) and the triglycerides in the lipid emulsions may increase blood and tissue fatty acid content. If usual metabolic pathways are saturated, these fatty acids would then be available for alternative reactions including both nonenzymatic and enzymatic lipid peroxidation. Because the rate limiting step in in vivo eicosanoid formation is the availability of substrate fatty acids, lipid emulsion-associated increases in fatty acids may increase the rate of eicosanoid formation. Lipid peroxides are one of the intermediate products in arachadonic acid oxidation (32); these oxidation reactions can also generate TBA reactants and pentane $(33,34)$. The data presented herein confirm the hypothesis that lipid peroxidation is increased by infusion of lipid emulsion preparations but do not clarify which specific pathways or reactions are involved. Vitamin $E$ is an effective antioxidant and when present in supraphysiologic amounts may have significant effects on eicosanoid formation in vivo. In vitro, vitamin $\mathrm{E}$ inhibits fatty acid release from phospholipids, inhibits lipoxygenase activity, and stimulates prostacyclin production (35). Thus, the "antioxidant actions" of vitamin E may have differential effects on lipid peroxidation depending on substrate availability and predominant oxidative pathways.

The third objective of these studies was to compare the antioxidant effectiveness of $\alpha$-tocopherol and $\alpha$-tocopheryl acetate in rabbit pups administered soybean oil emulsions. The acetate ester of $\alpha$-tocopherol may not be an antioxidant until the acetate group is replaced by a hydrogen. Although hydrolysis of the ester linkage occurs, $\alpha$-tocopherol concentrations in lung and liver after intravenous $\alpha$-tocopheryl acetate administration are lower than after intravenous $\alpha$-tocopherol (Table 5) (8). Despite these differences in tissue tocopherol concentrations, both forms of vitamin $E$ prevented the increases in expired ethane and pentane after infusion of soybean oil emulsion (Table 6). However, there were differences in tissue TBA reactants and lipid peroxides after $\alpha$-tocopherol or $\alpha$-tocopheryl acetate treatment. These differences appeared to be directly related to differences in tissue $\alpha$ - tocopherol concentrations. Administration of $\alpha$-tocopherol increased lung and liver $\alpha$-tocopherol concentrations and lowered lung and liver TBA reactants, and lung lipid peroxides. $\alpha$ Tocopheryl acetate administration increased only liver $\alpha$-tocopherol concentrations and lowered only liver TBA reactants; lung TBA reactants and lung lipid peroxides remained unchanged.

In newborn rabbits, infusion of either safflower or soybean oil lipid emulsion increased expired hydrocarbons. Infusion of soybean oil emulsion increased both expired ethane and pentane, while safflower oil emulsion increased only expired pentane (Table 3 versus 6). Dumelin and Tappel (36) demonstrated that production of specific hydrocarbons in vitro depends on the location of the $\omega$ double bond in the oxidized fatty acid. Ethane evolves from $\omega 3$ unsaturated fatty acids and pentane from $\omega 6$ fatty acids. Therefore, the observed increase in pentane without a change in ethane production after infusion of safflower oil emulsion (Table 3) is consistent with the lipid composition of this emulsion; 77\% linoleic acid $(\omega 6)$ and no linolenic acid $(\omega 3)$. Similarly, the increase in both ethane and pentane after infusion of soybean oil emulsion (Table 6 ) is consistent with soybean oil composition; $54 \%$ linoleic acid $(\omega 6)$ and $8 \%$ linolenic acid $(\omega 3)$.

Our results are similar to those reported by Wender et al. (37). In their study, rabbit pups fed a corn oil diet and exposed to hyperoxia had increased lung TBA reactants and increased erythrocyte hemolysis in hydrogen peroxide. Daily intramuscular injections of $20 \mathrm{mg} / \mathrm{kg}$ of $\alpha$-tocopherol prevented both of these increases. However, oxygen alone did not increase hydrogen peroxide-induced erthrocyte hemolysis; and lung TBA data from air exposed pups were not available for comparison with the lung TBA data from oxygen-exposed pups. It is possible that the fatty acids in the corn oil (58\% linoleic acid), and not the oxygen exposure, resulted in the increased lipid peroxidation. This conclusion is consistent with a previous report from our laboratory (14) and with the data in this report in which hyperoxia alone does not increase lipid peroxidation. Thus, the report from Wender et al. (37) may provide an enteral equivalent to our parenteral lipid infusion data.

In summary, this report demonstrates that high concentrations of oxygen alone do not increase lipid peroxidation above control values. Parenteral vitamin $\mathrm{E}$ decreases in vivo lipid peroxidation, however, $\alpha$-tocopheryl acetate is a less effective antioxidant than $\alpha$-tocopherol. The antioxidant effects seen in newborn rabbits justify a continued interest in the use of vitamin $E$, but also emphasize the need to understand better its sites, and mechanism, of action. The physiologic and metabolic consequences of changes in fatty acid oxidation, eicosanoid formation, and biologic radical generation and degradation are incompletely understood. The effects of large doses of $\alpha$-tocopherol on these enzymatic and nonenzymatic lipid peroxidation reactions may have major biologic significance. 


\section{REFERENCES}

1. Fridovich I 1976 Oxygen radicals, hydrogen peroxide and oxygen toxicity. In: Pryor WA (ed) Free Radicals in Biology, Vol I. Academic Press, NY, pp 239-277

2. Deneke SM, Fanburg BL 1980 Normobaric oxygen toxicity of the lung. $\mathrm{N}$ Engl J Med 303:76-86

3. Freeman BA, Crapo JD 1982 Biology of diseases: free radicals and tissue injury. Lab Invest 47:412-426

4. Frank L, Massaro D 1979 The lung and oxygen toxicity. Arch Intern Med 139:347-350

5. Bucher JR, Roberts RJ 1981 The development of the newborn rat lung in hyperoxia: a dose-response study of lung growth, maturation, and changes in antioxidant enzyme activities. Pediatr Res 15:999-1008

6. Gerdin E, Tyden O, Eriksson UJ 1985 The development of antioxidant enzymatic defense in the perinatal rat lung: activities of superoxide dismutase, glutathione peroxidase and catalase. Pediatr Res 19:687-691

7. Yam J, Frank L, Roberts RJ 1978 Oxygen toxicity: comparisons of lung biochemical responses in neonatal and adult rats. Pediatr Res 12:115-119

8. Knight ME, Roberts RJ 1985 Tissue vitamin E levels in newborn rabbits after pharmacologic dosing. Dev Pharmacol Ther 8:96-106

9. Phelps DL 1984 E-ferol: what happened and what now? Pediatrics 74:11141116

10. McCay PB, King MM 1980 Vitamin E: its role as a biologic free radical scavenger and its relationship to the microsomal mixed-function oxidase system. In: Machlin LJ (ed) Vitamin E: A Comprehensive Treatise. Dekker, New York, pp 289-317

11. Hittner HM, Speer ME, Rudolph AJ, Blifeld C, Chadd P, Holbein MEB, Godio LB, Kretzer FL 1984 Retrolental fibroplasia and vitamin E in the preterm infant - comparison of oral versus intramuscular: oral administration. Pediatrics 73:238-249

12. Wispé JR, Bell EF, Roberts RJ 1985 Assessment of lipid peroxidation in newborn infants and rabbits by measurements of expired ethane and pentane: influence of parenteral lipid infusion. Pediatr Res 19:374-379

13. Gutcher SR, Lax AA, Farrell PM 1984 Tocopherol isomers in intravenous lipid emulsions and resultant plasma concentrations. JPEN 8:269-273

14. Roberts RJ, Rednak I, Bucher JR 1983 Lipid peroxidation in the newborn rat: influence of fasting and hyperoxia on ethane and pentane in expired air. Dev Pharmacol Ther 6:170-178

15. Frank H, Hintze T, Bimboes D, Remmer H 1980 Monitoring lipid peroxidation by breath analysis: endogenous hydrocarbons and their metabolic elimination. Toxicol Appl Pharmacol 56:337-344

16. Mihara M, Uchiyama M, Fukuzawa K 1980 Thiobarbituric acid on fresh homogenate of rats as a parameter of lipid peroxidation in aging, $\mathrm{CCL}$ intoxication, and vitamin E deficiency. Biochem Med 23:302-311

17. Ohkawa H, Ohishi N, Yagi K 1979 Assay for lipid peroxides in animal tissues by thiobarbituric acid reaction. Anal Biochem 95:351-358

18. Aust SD, Svingen BA 1982 The role of iron in enzymatic lipid peroxidation. In: Pryor WA (ed) Free Radicals in Biology, Vol V. Academic Press, New
York, pp 1-28

19. Yagi K 1976 A simple fluorometric assay for lipoperoxide in blood plasma Biochem Med 15:212-216

20. Westerberg E, Friberg M, Akesson B 1981 Assay of brain tocopherols using high performance liquid chromatography. $J$ Liquid Chromatogr 4:109-121

21. Hicks M Gebicki JM 1979 A spectrophotometric method for the determination of lipid hydroperoxides. Anal Biochem 99:249-253

22. Rosner B 1982 Fundamentals of Biostatistics. Duxbury Press, Boston

23. Ehrenkranz RA 1980 Vitamin E and the neonate. Am J Dis Child 134:11571166

24. Bell EF, Filer LJ 1981 The role of vitamin $E$ in the nutrition of premature infants. Am J Clin Nutr 34:414-422

25. Slater RF 1984 Overview of methods for detecting lipid peroxidation. In: Packer L (ed) Methods in Enzymology, Vol 105, Academic Press, New York, pp 283-293

26. Tappel AL 1982 Measurement of in vivo lipid peroxidation via exhaled pentane and protection by vitamin E. In: Yagi K (ed) Lipid Peroxides in Biology and Medicine. Academic Press, New York, pp 213-222

27. Pryor WA, Castle L 1984 Chemical methods for the detection of lipid hydroperoxides. In: Packer L (ed) Methods in Enzymology, Vol 105. Academic Press, New York, pp 293-299

28. Cohen G 1982 Production of ethane and pentane during lipid peroxidation: Biphasic effect of oxygen. In: Yagi $\mathrm{K}$ (ed) Lipid Peroxides in Biology and Medicine. Academic Press, New York, pp 199-221

29. Knight ME, Wispé JR, Roberts RJ 1985 Antioxidant properties of pharmacologic doses of vitamin $\mathrm{E}$ in newborn rabbits. Pediatr Res 19:174(abstr)

30. Flohe L 1982 Glutathione peroxidase brought into focus. In: Pryor WA (ed) Free Radicals in Biology, Vol V. Academic Press, New York, pp 223-254

31. Kao LC, Cheng MH, Warburton D 1984 Triglycerides, free fatty acids/albumin molar ratio, and cholesterol levels in serum of neonates receiving long-term lipid infusions: controlled trial of continuous and intermittent regimens. $J$ Pediatr 104:429-435

32. Hayaishi O, Shimizu T 1982 Metabolic and functional significance of prostaglandins in lipid peroxide research. In: Yagi $\mathrm{K}$ (ed) Lipid Peroxides in Biology and Medicine. Academic Press, New York, pp 41-53

33. Pryor WA, Stanley JP, Blair E 1976 Autooxidation of polyunsaturated fatty acids: II. A suggested mechanism for the formation of TBA-reactive materials from prostaglandin-like endoperoxides. Lipids 11:370-379

34. Evans CD, List GR, Doley A, McConnell DG, Hoffmann RL 1967 Pentane from thermal decomposition of lipoxidase-derived products. Lipids 2:432434

35. Panganamala RV, Cornwell DG 1982 The effects of vitamin E on arachadonic acid metabolism. Ann NY Acad Sci 293:376-391

36. Dumelin EE, Tappel AL 1977 Hydrocarbon gases produced during in vitro peroxidation of polyunsaturated fatty acids and decomposition of preformed hydroperoxides. Lipids 12:894-900

37. Wender DF, Thulin GE, Smith GJW, Warshaw JB 1981 Vitamin E affects lung biochemical and morphologic response to hyperoxia in the newborn rabbit. Pediatr Res 15:262-268 